
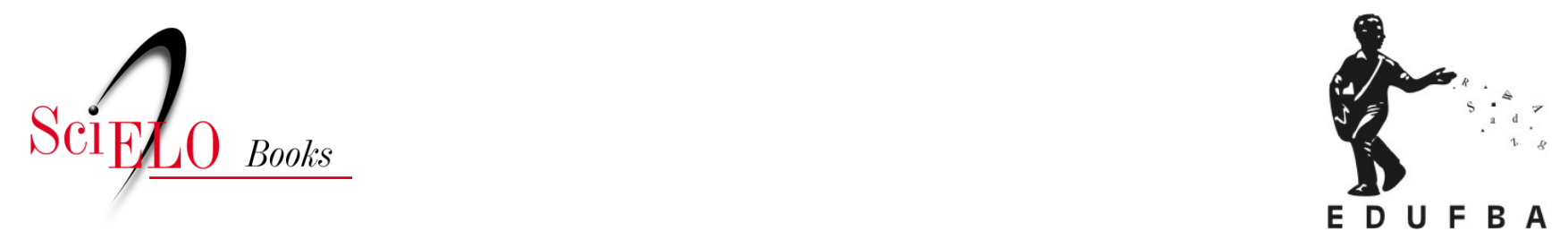

\title{
Psicologia e interfaces pedagógicas O papel do professor na formação moral e ética de estudantes universitários
}

\author{
Elzenita Falcão de Abreu \\ Heloisa Moulin de Alencar
}

ABREU, E.F., and ALENCAR, H.M. O papel do professor na formação moral e ética de estudantes universitários. In: SANTIAGO, A.M.S., and FONSÊCA, A.L.B., comp. Psicologia e suas interfaces: estudos interdisciplinares [online]. Salvador: EDUFBA, 2016, pp. 219-232. ISBN 978-85-232-2007-5. https://doi.org/10.7476/9788523220075.0009.

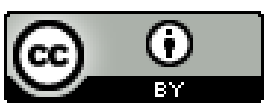

All the contents of this work, except where otherwise noted, is licensed under a Creative Commons Attribution 4.0 International license.

Todo o conteúdo deste trabalho, exceto quando houver ressalva, é publicado sob a licença Creative Commons Atribição 4.0. 


\section{O papel do professor na formação moral e ética de estudantes universitários}

Elzenita Falcão de Abreu, Heloisa Moulin de Alencar

Introdução

Constatamos que mudanças e progressos decorrentes, principalmente, das rápidas e profundas transformações tecnológicas vêm exigindo substanciais modificações na atividade educativa e na prática docente nos seus diferentes contextos de atuação. Na opinião de Candau (1991), um projeto de inovação tecnológica na educação deve gerar propostas comprometidas com as finalidades educativas, assumindo como essencial o sentido transformador da prática pedagógica. Para Demo (1998), a função básica do professor não é mais dar aula, e sim orientar o processo reconstrutivo do aluno, por meio da avaliação permanente, do suporte em termos de materiais a serem trabalhados, da motivação constante e da organização sistemática do processo. Esse conjunto de fatores vem promovendo novas formas de relação entre professores e alunos e pode favorecer ou não vivências que contribuem para a qualidade de vida dos mesmos. 
Mercado (1998) concebe que é função dos professores recriar sistematicamente, pois, quando atuam em diferentes contextos, encontram alunos com características diversificadas, fato que acontece em todos os níveis de ensino. Além disso, considera que a sociedade do conhecimento vem exigindo do professor um novo perfil. Dele é exigido que seja: comprometido, competente, crítico, aberto às mudanças, exigente e interativo, características que vão além da construção e produção do conhecimento. É também preciso que o espaço da aula seja adequado aos trabalhos coletivos, que favoreça o processo de interação aluno-aluno e aluno-professor.

Brito (2006) reconhece o trabalho docente como complexo e que a trajetória profissional é demarcada por diferentes experiências pessoais, profissionais e por vivências de interações estabelecidas no dia a dia. Com isso, cabe ao professor procurar uma postura ativa de reflexão e buscar reciclar-se para acompanhar as diferentes demandas que surgem no cotidiano de sua prática.

Tanto Jafelicci Júnior (2002) como Di Santo ([2007]) ressaltam o papel social dos docentes e sua importância na formação pessoal e profissional do discente. Ambos concebem que esse papel vai além de facilitador do processo de aprendizagem do aluno e transmissor dos conteúdos das disciplinas. Para o primeiro autor, o professor tem também a responsabilidade de promover o envolvimento do aluno nas diferentes experiências de aprendizagem e contribuir com a sua formação enquanto cidadão e futuro profissional. Por sua vez, para a segunda autora, os docentes transmitem uma filosofia de vida, porque o relacionamento entre professores e alunos está norteado por valores morais e éticos que constituem as condutas que eles desenvolvem e caracterizam seus posicionamentos no mundo. Essas considerações nos levam a conceber que toda a prática pedagógica é inspirada em princípios determinados por valores, que possibilitam a compreensão e interpretação das regras. Logo, podemos dizer que a moral se encontra implícita na prática pedagógica. (PEREIRA, 2008) 


\section{Moral e ética}

A moral para La Taille (2006) diz respeito aos sistemas de regras e princípios que respondem à pergunta “como devo agir?”. Concebe a experiência subjetiva de um sentimento de obrigatoriedade, em todas as pessoas, que possibilita o cumprimento dos deveres. Contudo, para esse autor, os deveres que emanam da moral precisam ser considerados dentro de um projeto de "vida boa", de um projeto de felicidade relacionado ao plano ético, porque é preciso conhecer a perspectiva ética adotada, para poder compreender o processo que os leva a respeitar suas ações morais. Dessa forma, La Taille (2006) relaciona a ética à reflexão "que vida eu quero viver?"ou "que vida vale a pena ser vivida?”, agora nos remetendo a uma aspiração e não a um dever.

Para La Taille (2006), o sujeito moral faz uso da razão para compreender e interpretar as regras, sendo capaz de utilizar critérios para julgar e decidir como agir. Essa dimensão intelectual relacionada ao "fazer moral" o torna livre para estabelecer suas escolhas. O sujeito moralmente autônomo, tal como o sujeito heterônomo, é inspirado pelo sentimento de obrigatoriedade, mas ele elege os conteúdos para a sua moral, devendo ter a equidade e a reciprocidade como princípios de seus juízos e ações morais. Ressaltamos, ainda conforme La Taille (2006), que devemos definir conteúdos apenas para a moral, porquanto é ela que confere às opções de "vida boa" sua legitimidade, e não devemos escolher conteúdos para a ética, uma vez que são inúmeras as opções para a expansão de si e cada pessoa tem liberdade de escolher que rumo dar à própria vida.

A partir da concepção de que devemos escolher deveres morais, o autor, nessa citada obra, elege, define e explica as virtudes morais: justiça, generosidade e honra, considerando-as condicionadas pelo imperativo categórico kantiano: "cada ser humano deve sempre tratar a humanidade, em outrem e em si próprio, como um fim e nunca como meio. A premissa desse imperativo é que existe uma dignidade 
inerente a cada ser humano e que ela deve ser estritamente respeitada”. (LA TAILLE, 2006)

Além da dimensão intelectual, La Taille (2006) também concebe a existência da dimensão afetiva da moral, na qual se encontra envolvido o sentimento que impulsionará o sujeito à ação. Trata-se do "querer fazer", pois é preciso escolher quais são esses deveres e que essa escolha tenha um sentido existencial para ele, ou seja, que a felicidade individual procurada se estenda a todos os seres humanos e tenha, assim, legitimidade social. No entanto, nem sempre se é capaz de analisar as implicações das ações praticadas. Torna-se necessário ter sensibilidade moral para conseguir identificar os elementos moralmente relevantes, ou seja, aqueles que podem ser considerados dentro de um projeto que tenha sentido no plano ético.

Diante dessas considerações, levantamos algumas indagações sobre como os temas moral e ética vêm sendo abordados e compreendidos no meio educacional. Será que apenas o discurso vem ocupando esses espaços e não se tem dado à ética a devida importância na prática? Qual o papel dos professores nesse processo de formação?

\section{A moral e a ética na prática pedagógica}

Para Goergen (2005, p. 985), o que se tem constatado é “[...] que a ética ocupa um lugar bastante singelo, muitas vezes restrito a um recorte disciplinar ou, quando muito, a uma atividade transversal”. Visto dessa forma, trata-se de uma proposta no sentido de chamar a atenção para os direitos e deveres, enfatizando regras e normas consideradas certas ou erradas. A preocupação parte do interesse que os professores têm em ensinar as regras e normas aos alunos, e não de experenciarem juntos a "vida boa" no cotidiano da escola, na qual o autorrespeito e o respeito pelo outro devem estar presentes em todas as ações, conforme propõe La Taille (2006).

De acordo com Costa (2001), o ambiente escolar é um espaço privilegiado de aprendizagem e, segundo Vasconcelos (2006), professores e alunos são figuras centrais nesse processo, mas cabe ao do- 
cente promover e transformar o espaço educativo em ambiente de confiança e aprendizagem. Assim, mais importante que o discurso verbal é a discussão estabelecida com os alunos sobre as responsabilidades de cada um e sobre os valores e princípios, que dão sentido à vida, entre outras questões. Porém, é fundamental que os conteúdos dessas discussões tenham repercussões no dia a dia da escola e envolvam todos que dela fazem parte, como diretores, professores, alunos e funcionários em geral.

Hargreaves e Fullan (2006) acreditam que o professor exerce influência na formação profissional e pessoal dos alunos na infância e adolescência, mas pode perdurar até a fase adulta. Entendem que essa influência é exercida, sobretudo, pelas crenças, convicções e valores pessoais, que são transmitidos no desenvolvimento de suas práticas e vivências, e esses nem sempre são claramente percebidos. Muitas vezes, os alunos que se encontram em processo de construir suas formas de concepções de homem e de mundo não conseguem identificar o tipo de influência que estão absorvendo, pois essa pode ser positiva ou negativa. Também Lazzarin, Nakama e Cordoni Junior (2007) concluíram, pelo resultado da pesquisa realizada, que o professor é considerado responsável não só pela transmissão dos conhecimentos como também das experiências. Outro aspecto interessante que encontraram foi quanto à escolha pelos acadêmicos do que eles chamaram de "professores marcantes". Essa caracterização está relacionada à valorização que dão à prática social desenvolvida pelo profissional, levando-os a ter admiração pelos mesmos.

O estudo de Cunha (2006) trata da concepção do que é ser um bom professor. A autora apresenta os resultados de uma pesquisa interinstitucional que investigou o Exame Nacional de Cursos, conhecido como "provão". Entrevistaram alunos, coordenadores e professores de cursos de graduação, pertencentes a instituições de ensino superior do estado do Rio Grande do Sul. Ouviram professores de 10 cursos, utilizando entrevistas em que foram instados a falar das suas trajetórias acadêmicas e experiências educativas e das 
suas percepções referentes aos processos de avaliação externa, especialmente o "provão". Partiu do pressuposto de que os saberes considerados legítimos são decorrentes da concepção do que seja um bom professor e agrupou os depoimentos em categorias, da seguinte forma:

1) saberes relacionados com o conteúdo da matéria de ensino;

2) saberes relacionados com a prática pedagógica, envolvendo desde o "saber transmitir" até o motivar os alunos e entender como os mesmos aprendem;

3) saberes que decorrem de uma postura ética, que torna o professor um educador, na concepção dos nossos interlocutores; e

4) saberes próprios das posturas e atividades investigativas, entendidos como aqueles que fazem do professor um produtor do conhecimento.

Com base nos depoimentos de seus respondentes, chegou à conclusão de que

[...] é possível fazer uma projeção de habilidades e competências necessárias aos professores que envolvem relativa complexidade. Ao mesmo tempo, é possível notar que os saberes que eles afirmam mobilizar estão ligados a uma compreensão de docência que extrapola a dimensão da racionalidade técnica. Incluem capacidades complexas e amplas, envolvendo diferentes perspectivas intelectuais, afetivas, morais e culturais. Se essa é a projeção de docência de qualidade que fazem os professores, imagina-se que seja, também, a balizadora da sua autocrítica e avaliação. Tudo indica que os professores gostariam de se aproximar desse patamar de desempenho. (CUNHA, 2006, p. 263)

As discussões incitam reflexões sobre os sentidos e significados das experiências vividas pelos estudantes no contexto da formação universitária. Isso porque entendemos que a formação do aluno é uma construção coletiva sujeita a uma série de influências, e o professor é 
o elemento fundamental nesse complexo de relações. Conforme afirma Cunha(2006, p. 259), "todos os professores foram alunos de outros professores e viveram as mediações de valores e práticas pedagógicas. Absorveram visões de mundo, concepções epistemológicas, posições políticas e experiências didáticas”.

A universidade é um importante espaço que visa, especialmente, a formação profissional. No entanto, há uma expectativa de que essa preparação de profissionais vá além da competência técnica, que esteja atenta à formação do desenvolvimento pessoal dos estudantes. Silva e Cunha (2002), por exemplo, esperam que a educação neste século esteja voltada para a instauração de princípios éticos de compreensão e solidariedade, além da ampliação da capacidade intelectual dos seus alunos. Nesse contexto, entendem que a universidade tem seu papel ampliado no sentido de reforçar o aumento dos valores éticos e morais da sociedade. Dela se espera a promoção do pensamento científico, o cultivo de mentes criadoras e imaginativas, e que, juntamente com a preparação para a vida profissional, seja dada maior ênfase para o desenvolvimento pessoal dos estudantes, considerando que a formação humana é fundamental no contexto da sociedade do conhecimento. (SILVA; CUNHA, 2002)

Ainda sobre a universidade, Teixeira (2001, p. 6) declara que "é o lugar da proposição do novo, a instância de onde poderá provir a alternativa mais adequada ao tratamento das grandes questões que nos motivam e inquietam". Cabe a ela indicar os rumos da transformação social e do progresso da civilização. Sendo assim, o ensino superior deve buscar os anseios da sociedade, procurando responder aos questionamentos mais pertinentes e criticar o conhecimento produzido, tendo sempre como foco os futuros profissionais que atuarão na sociedade. (PIMENTA, 2002)

A partir dessas perspectivas, há de se repensar o papel do educador. Espera-se que este seja, sobretudo, um incentivador, para que o estudante saiba não só se valer do conteúdo de informações postas à sua disposição, mas também selecionar dentre elas as mais 
úteis. De acordo com Teixeira (2001), esse conjunto de fatores exige mudanças significativas no nível de profissionalismo dos docentes, uma vez que se aprende de muitas formas. Para ele, não faz sentido insistir em aulas expositivas e tradicionais simplesmente, quando há, com as novas tecnologias, disseminação das informações e a possibilidade de comunicação em tempo real, para qualquer pessoa dotada de um mínimo de curiosidade. Sendo assim, a transmissão do conteúdo não deve ser centrada apenas no conhecimento técnico, mas na experiência de vida, na criatividade e disponibilidade do docente.

Candau (1991) também entende que a inovação tecnológica afeta diretamente a profissão docente e implica em necessárias transformações na prática pedagógica. Conforme a autora, a ênfase na transmissão do conhecimento pronto continua fazendo parte da didática do professor, pois o processo educativo, na maior parte das vezes, não estimula a consciência de que todo conhecimento é provisório, que está em contínuo processo de criação e recriação. Como diz Demo (1998), do professor orientador da organização do processo reconstrutivo do aluno, são exigidas algumas capacidades, como: postura democrática, criatividade, habilidades para resolver problemas, trabalhar em equipe, e estas, muitas vezes, independem do esforço pessoal, pois envolvem a instituição de ensino como um todo.

Além da exigência de uma preparação adequada para o exercício da docência, como as citadas por Demo (1998), o educador também deve ser cobrado quanto ao compromisso político. É que parece indispensável para a formação universitária, hoje, uma observação na nossa realidade política em elaboração, e o professor na sua fala, no seu ensinar, deve pôr o conhecimento em relação com o contexto da sociedade a que se aplica, para tornar o processo educativo mais autêntico. (FREIRE, 2002) Nesse sentido, essa espécie de controle da ação pedagógica docente pode ter repercussões positivas, levando-o a procurar uma postura ativa de reflexão, autoavaliação e de estudo constante, ou desencadear um comportamento defensivo que pode, em curto prazo, provocar a sensação de estar atendendo às demandas 
sociais e gerar acomodação. Isso nos leva a refletir se essas exigências, decorrentes das constantes modificações no mundo, na sociedade e na comunidade escolar em geral têm sido assimiladas como uma oportunidade de crescimento profissional, ou como uma ameaça que dificulta o desenvolvimento da prática educativa.

Sobre a universidade e o papel do professor universitário, Jafelicci Júnior (2002) relata ao informativo Proex, entre outras coisas, a relevância do papel dos docentes que atuam nas áreas de pesquisa, ensino e extensão. Para ele, o professor universitário pode ser considerado a figura principal nas ações dessas três áreas que dinamizam a universidade. Dentre as inúmeras expectativas criadas sobre o seu papel de educador, ele é considerado como o cérebro pensante dos problemas sociais e facilitador da aprendizagem dos educandos.

Quanto às funções docentes, Di Santo ([2007]) considera que não devem ser restritas à transmissão dos conteúdos das disciplinas, mas, também, uma filosofia de vida, uma visão de mundo, a qual é passada para o aluno por meio das opiniões que emitem, das discussões que provocam e nas reflexões que propõem. Finaliza afirmando que os princípios que orientam a prática do professor fazem com que ele eduque mais pelo que é do que pelo conteúdo que transmite. É um desafio intenso, que exige desse educador, dentre outras coisas, uma postura crítica, principalmente quando traz para si a responsabilidade pela formação do aluno.

Diante desse panorama, concordamos com Pereira (2008, p. 15) quando afirma que a moral se encontra implícita na prática pedagógica, também porque nos diz que “[...] a moralidade é algo que se constrói no homem por inteiro, desde a dimensão teórica da concepção de valores e princípios, até a dimensão prática da ação”. Assim, compreendemos que toda a prática carrega consigo uma formação inspirada em princípios que levam à formulação das regras e ao conjunto de deveres. Esses princípios são determinados pelos valores construídos e irão fazer compreender e interpretar as regras. 
La Taille $(2006,2009)$ relaciona essa capacidade para compreender e interpretar as regras à participação da razão no "fazer moral”. Para o autor, o "saber fazer" é resultado da liberdade que o indivíduo tem para agir (fazer), tomar decisões baseadas no seu potencial intelectual, ou seja, na capacidade que tem o indivíduo de refletir e julgar como deve ou não conduzir sua vida. O autor concebe, além dessa dimensão da moral chamada intelectual, a existência da dimensão afetiva da moral para justificar a necessidade do "querer fazer", pois alguém só será realmente um ser moral se isso fizer sentido existencial para ele. Essa dimensão afetiva se refere à energia despendida para realizar a ação.

Partindo dessa concepção, o uso da razão nos permite empregar critérios e escolher as ações que devemos desenvolver, mas o sentimento envolvido desencadeará a ação. No entanto, La Taille (2009) enfatiza que é preciso ter sensibilidade moral para conseguir inferir e identificar os elementos moralmente relevantes, pois nem sempre se é capaz de analisar as implicações das ações praticadas. Os critérios escolhidos (razão) e o sentimento envolvido (afetividade), para serem morais, devem ser considerados dentro de um projeto de vida boa, de uma vida que inclua o respeito pela dignidade alheia e pela justiça, ou seja, que tenha sentido no plano ético. (LA TAILLE, 2006)

Na opinião de Pereira (2008, p. 8) é comum observar nos professores o interesse em estudar questões relativas à ética, à moral e aos valores, no intento de ensiná-los na escola. Todavia, nota-se que eles se preocupam em conceituar os temas no sentido de identificar o que seria certo ou errado de acordo com os padrões éticos, interesse que considera válido. Porém, faltam-lhe associar a esse interesse outro "capaz de transformar o cotidiano segundo valores exaltados pela ética e pela moral”.

Verificamos que essas questões vêm sido discutidas pela sociedade e suas instituições, sobretudo nas de ensino, uma vez que criar cidadãos éticos deve ser responsabilidade de todos. Pereira (2008, p. 8) acredita que "quando observamos a sociedade contemporânea, facil- 
mente percebemos um clamor pela moralidade e pela fundamentação das ações individuais e coletivas nos valores humanos”. Ressalta que a mídia tem nos mostrado uma expansão dos campos dos direitos humanos da bioética, da ética e da moral. No entanto, essa crescente motivação pela defesa da ética e da moral não é suficiente: precisa-se saber como é compreendida a formação do comportamento ético e moral, que concepções ideológicas, valores e informações são promovidos. (PEREIRA, 2008) Na compreensão de Heck (1995, p. 363), igual a qualquer outro discurso, o da ética e da moral carece de seriedade intelectual. Isso porque entende que “[...] querer praticar o bem, sem a mínima pretensão de saber o que é bom, honra tão pouco uma pessoa de bem quanto desonra um homem de ciência ignorar o que é feito com a sua ciência”.

Considerando essas explanações, retomamos o questionamento a respeito de qual seria o papel do professor nesse contexto de formação. Retomando Costa (2001), sua compreensão é de que o professor é mais que um simples cidadão, é um produtor de cidadania dentro e fora da sala de aula. Suas práticas e vivências constituem um espaço privilegiado para que se possa aprender convivendo com as experiências e acontecimentos por ele proporcionados. Porque, para o autor, “[...] todo ato humano consequente depende de uma decisão prévia daquele que realiza este ato. E os valores é que irão determinar a atitude das pessoas". (COSTA, 2001, p. 92) Os valores não existem simplesmente, precisam ser experimentados. Do cotidiano das ações docentes, fazem parte os alunos que estabelecem com eles variados tipos de relações promotoras de aprendizagem. Práticas e vivências devem ser oferecidas para facilitar a discussão, a identificação e a incorporação de valores pelos alunos. É preciso buscar, nos seus contextos pessoal e interpessoal, temas que consigam levá-los a evocar os conteúdos de suas vivências para que consigam construir a representação de si mesmo e do mundo que orientará sua caminhada e guiará suas escolhas. Quando há preocupação com a formação ética, são discutidas as relações com o outro, bem como as responsabilidades de cada um e os princípios e valores que dão sentido à vida. 
Vasconcelos (2006, p. 21) também faz referência ao papel do docente dizendo que "[...] a figura do professor deve ser ressaltada como sendo aquela que imprime sentido a esta relação na qual professor e aluno ocupam lugares e papéis já demarcados, aprioristicamente determinados pela instituição que os abriga”. Acrescenta realçando que, na educação superior, esse relacionamento é de fundamental importância e deve ser próximo para que o diálogo seja facilitado, contudo não deve ser tão íntimo para que não descaracterize os papéis de professor e aluno, tornando-os iguais. Com essas considerações, percebemos que uma das parcelas da função docente está relacionada à atenção que devem ter ao local de sua inserção na instituição e no vínculo que se estabelece com os discentes, a fim de promover a transformação do espaço educativo em espaço de respeito, confiança e aprendizagem.

\section{Considerações finais}

Perante essas colocações, fica claro que o papel do professor não se limita ao conhecimento da disciplina que ministra e nas diferentes atividades acadêmicas que desenvolve. Concebemos que eles também são valorizados pelo desempenho como profissionais da área (LAZZARIN; NAKAMA; CORDONI JUNIOR, 2007) e pela maneira como se relacionam com os alunos. Logo, além do saber constituído na sua formação profissional, outros valores se encontram envolvidos e são transmitidos no processo de ensino-aprendizagem. Como diz Cunha (2006), as capacidades envolvidas na prática docente devem envolver perspectivas que vão além da racionalidade para que seja atingido esse patamar de desempenho. Consideramos que esse patamar pode ser alcançado pelo professor que sabe ouvir, respeitar, conviver com a diferença, ser honesto e justo nas avaliações, além de outras condutas inspiradas em princípios éticos.

Concluindo, vimos que os teóricos apontam o professor como o elemento fundamental na formação do aluno, embora essa formação seja uma construção coletiva. Ele é um personagem ativo nesse pro- 
cesso, também sujeito a uma série de influências, que vão repercutir na sua prática e na preparação dos futuros profissionais.

\section{Referências}

BRITO, A. E. O significado da reflexão na prática docente e na produção dos saberes profissionais do/a professor/a. Revista Iberoamericana de Educación, Madrid, v. 38, n. 7, p. 139-158, 2006.

CANDAU, V. M. Informática na Educação: um desafio. Tecnologia Educacional, Rio de Janeiro, v. 20 n. 98-99, p. 14-23, 1991.

COSTA, A. C. G. O professor como educador: um resgate urgente e necessário. Salvador: Fundação Luís Eduardo Magalhães, 2001.

CUNHA, M. I. da. Docência na universidade, cultura e avaliação institucional: saberes silenciados em questão. Revista Brasileira de Educação, Rio de Janeiro, v. 11, n. 32, p. 258-371, 2006.

DEMO, P. Professor \& teleducação. Tecnologia Educacional, Rio de Janeiro, v. 26, n. 143 , p. 52-63, 1998.

DI SANTO, J. M. R. Di Santo JMR. Portfólio como auto-regulação da aprendizagem no ensino superior. [S.I.]: Centro de Referência Educacional, [2007]. Acesso em: <http://www.centrorefeducacional.com.br/fundocen. htm>. Disponível em: 20 Jul. 2009.

FREIRE, P. Educação e atualidade brasileira. 2. ed. São Paulo: Cortez, 2002.

FURLANI, D. D.; BOMFIM, Z. A. C. Juventude e afetividade: tecendo projetos de vida pela construção dos mapas afetivos. Psicologia \& Sociedade, Belo Horizonte, v. 22, n. 1, p. 50-59, 2010.

GOERGEN, P. Educação e valores no mundo contemporâneo. Educação \& Sociedade, Campinas, v. 26, n. 92, p. 983-1011, 2005.

HARGREAVES, A. FULLAN, M. Como trabalhar o poder da influência?. [S.I.], 2006. Disponível em: <http://www.universia.com.br/materia/materia. jsp? materia $=10304>$. Acesso em: 11 jun. 2009.

HECK, J. N. Da teoria e da prática do bem uma abordagem filosófica do clamor por mais ética na política. Síntese Nova Fase, Belo Horizonte, v. 22, n.70, p. 351-365, 1995. 
JAFELICCI JÚNIOR, M. O papel social dos professores universitários. [S.I.], 2002. Disponível em: <http://www.unesp.br/proex/informativo/edicao22dez2002 / materias/professorsocial.htm>. Acesso em: 20 jul. 2009.

LA TAILLE, Y. de. Construção da consciência moral. Prima Facie: revista de ética, Portugal, Faro, v. 2, p. 7-30, 2009.

LA TAILLE, Y. de. Moral e ética: dimensões intelectuais e afetivas. Porto Alegre: Artmed, 2006.

LAZZARIN, H. C.; NAKAMA, L.; CORDONI JUNIOR, L. O papel do professor na percepção dos alunos de odontologia. Saúde e Sociedade, São Paulo, v. 16, n. 1, p. 90-101, 2007.

MERCADO, L. P. L. Formação docente e novas tecnologias. In: CONGRESSO DA REDE IBEROAMERICANA DE INFORMÁTICA EDUCATIVA, 4., 1998. Brasilia, DF. Anais... Brasília, DF: RIBIE, 1998. p. 1-8. Disponível em: <http://www.cedu. ufal.br/projetos/internet/brasiliadef.htm>. Acesso em: 12 dez. 2011.

PEREIRA, B. Q. Inferências sobre a educação ética e moral a partir de Yves de La Taille: o sentimento de autoestima e autorrespeito em resposta de professores em situações simuladas de convívio com estudantes. 2008. 74 f. Dissertação (Mestrado em Educação) - Universidade Católica de Santos, 2008.

PIMENTA, S. G. Docência no ensino superior: construindo caminhos. Revista de Educação CEAP, Salvador, v. 10, n. 36, p. 103-114, 2002.

SILVA, E. L.; CUNHA, M. V. A formação profissional no século XXI: desafios e dilemas. Ciência da Informação, Brasília, DF, v. 31, n. 3, p. 77-82, 2002.

TEIXEIRA, S. de F. A universidade: compromisso com a excelência e instrumento de transformação. Jurisprudência do Superior Tribunal de Justiça, Brasília, DF, v. 2, n. 17, p. 79-87, 2001.

VASCONCELOS, M. L. Autoridade docente no ensino superior: discussão e encaminhamentos. São Paulo: Xamã; Niterói: Intertexto, 2006. 